\title{
Stage IV Appendix Carcinoma AJCC v8
}

National Cancer Institute

\section{Source}

National Cancer Institute. Stage IV Appendix Carcinoma A/CC v8. NCI Thesaurus. Code C134129.

Stage IV includes: IVA: (Any T, N0, M1a); (Any T, Any N, M1 b, G1); IVB: (Any T, Any N, M1b, G2, G3, or GX); IVC: (Any T, Any N, M1c, Any G). N0: No regional lymph node metastasis. M1a: Intraperitoneal acellular mucin, without identifiable tumor cells in the disseminated peritoneal mucinous deposits. M1b: Intraperitoneal metastasis only, including peritoneal mucinous deposits containing tumor cells. M1c: Metastasis to sites other than peritoneum. G1: Well differentiated. G2: Moderately differentiated. G3: Poorly differentiated. GX: Grade cannot be assessed. (AJCC 8th ed.) 